\title{
COCRYSTALLIZATION ACYCLOVIR-SUCCINIC ACID USING SOLVENT EVAPORATION METHODS
}

\section{AGNES NUNIEK WINANTARI ${ }^{1,2}$, DWI SETYAWAN ${ }^{2 *}$, SISWANDONO SISWODIHARDJ0², SUNDONO NURONO SOEWANDHI ${ }^{4}$}

\begin{abstract}
${ }^{1}$ Department of Pharmaceutics, Faculty of Pharmacy, University of Surabaya, Surabaya, Indonesia. ${ }^{2}$ Department of Pharmaceutics, Faculty of Pharmacy, Airlangga University, Surabaya, Indonesia. ${ }^{3}$ Department of Medicinal Chemistry, Faculty of Pharmacy, Airlangga University, Surabaya, Indonesia. ${ }^{4}$ Department of Pharmaceutics, School of Pharmacy, Bandung Institute of Technology, Bandung, Indonesia Email: dwisetyawan-90@ff.unair.ac.id
\end{abstract}

Received: 28 November 2016, Revised and Accepted: 09 March 2017

ABSTRACT

Objective: The aim of this research is to prepare and characterize cocrystals of acyclovir through cocrystallization of acyclovir-succinic acid (AS) to improve the physical properties of the drug.

Methods: AS cocrystals were prepared using solvent evaporation method. The cocrystals were characterized by polarization microscope, scanning electron microscopy (SEM), differential scanning calorimetry, powder X-ray diffraction (PXRD), and Fourier transform infrared spectroscopy.

Results: Physical characterization using polarization microscope and SEM showed the AS cocrystals have unique crystal habit and morphology. Phase diagram at a molar ratio of 50:50\% (acyclovir:succinic acid) showed a decrease in the melting temperature, i.e., $176.23^{\circ} \mathrm{C}$ in comparison with the melting point of the constituent materials (acyclovir $253.53^{\circ} \mathrm{C}$ and succinic acid $187.29^{\circ} \mathrm{C}$ ). The PXRD pattern of AS cocrystals (ethanol) exhibited new diffraction peaks at $2 \theta=5.91^{\circ} ; 9.16^{\circ}$; and $13.40^{\circ}$. Besides, cocrystals of AS (glacial acetic acid) indicated new peaks at $2 \theta=5.98^{\circ}$; $9.19^{\circ}$; and $13.43^{\circ}$. Furthermore, there was a shift in the $\mathrm{N}-\mathrm{H}, \mathrm{O}-\mathrm{H}$, and $\mathrm{C}=\mathrm{O}$

Conclusion: Cocrystallization of AS acid in ethanol and glacial acetic acid were successfully formed using solvent evaporation methods.

Keywords: Acyclovir-succinic acid, Cocrystal, Characterization, Solvent evaporation method.

(C) 2017 The Authors. Published by Innovare Academic Sciences Pvt Ltd. This is an open access article under the CC BY license (http://creativecommons. org/licenses/by/4. 0/) DOI: http://dx.doi.org/10.22159/ajpcr.2017.v10i6.16369

\section{INTRODUCTION}

The properties of the pharmaceutical solid such as solubility and dissolution rate are important as the ability to manufacture the solid dosage form at scale. Attempting to find a solid with the desired properties and manufacturability, companies spend significant effort looking for polymorphs, salts, and cocrystal of their active pharmaceutical ingredients (API's) [1-5].

Cocrystal is a homogenous crystalline material composed of a neutral target and a neutral coformer held together through noncovalent bonds. For pharmaceutical applications, it is essential that the coformers have generally recognized as safe status. The physicochemical properties of API's can be modified while the intrinsic activities of these drug molecules remain the same. From the thermodynamic point of view, pharmaceutical cocrystals are stable and high energy forms. Therefore, they can have impact on solubility and dissolution rate of the drug. The strategy involves drug-coformer combinations that have the potential of forming energetically and structurally robust interactions [3-8]. Pharmaceutical cocrystals often rely on hydrogen-bonded assemblies between an API and coformer with well-defined stoichiometries. For a target API, we are interested in coformers with functional groups that can interact (i.e., form $\mathrm{H}$-bonds) with the functional groups on the API. Common functional groups - such as carboxylic acids, amides, and alcohols - are typically found to interact with one another in cocrystals $[3,9,10]$.

Acyclovir, a guanosine analog antiviral drug with a solubility of $1.62 \mathrm{mg} / \mathrm{mL}$. Due to its poor solubility and permeability, the bioavailability of acyclovir attains just 15-30\% [11-14]. Carboxylic acids are considered as coformers to form cocrystals with acyclovir. A group of carboxylic acids including succinic acid, glutaric acid, and adipic acid [13].

Solvent evaporation is the most conventional technique of cocrystallization which includes super saturation of solution by evaporation, cooling and addition of solubility changing solvent or substance [15].

The aim of this research was to prepare and characterize cocrystals of acyclovir through cocrystallization of acyclovir-succinic (AS) acid to improve the physical properties of the drug. The obtained of cocrystals were characterized by microscope polarization, scanning electron microscopy (SEM), differential scanning calorimetry (DSC), powder $\mathrm{X}$-ray diffraction (PXRD), and Fourier transform infrared spectroscopy (FTIR).

\section{MATERIALS AND METHODS}

Materials

Acyclovir commercial material was obtained from Sigma (USA). Succinic acid, ethanol, and glacial acetic acid were purchased from Merck Chemicals (Germany) without any purification.

\section{Methods}

\section{Phase diagram preparation of AS acid}

AS acid was sifted and weighed to obtain a similar range of particle size. Both of samples were mixing at different molar ratios, i.e., $(10 / 90),(20 / 80),(30 / 70),(40 / 60),(50 / 50),(60 / 40),(70 / 30)$, $(80 / 20)$, and $(90 / 10)$ to obtain the AS physical mixture. The mixture was gently mixed in a mortar for 5 minutes. Examination of melting point of AS physical mixture was determined by DSC. Phase diagram of AS describes the molar fraction of the mixture against the endothermic peak [16]

\section{Preparation of AS cocrystals by solvent evaporation}

AS acid carefully weighed equimolar. Each compound was dissolved in ethanol separately. The both of solutions were mixed and stirred for a few minutes. Equimolar solution of both components was evaporated 
at room temperature for 48 hrs. The obtained cocrystal solids were stored in a desiccator under vacuum [17].

\section{Characterization by polarized microscope}

About 1-2 mg of physical mixture between AS acid was placed on object glass. A drop of ethanol was added to each physical mixture until dissolved and allowed to recrystallize. Recrystallization process was observed under a polarizing microscope. The microscopic images were recorded with an Olympus SC-30 digital color camera attached to the Olympus BX-50 polarized microscope [18].

\section{Characterization using SEM}

Sample was placed on the sample holder and coated with gold aluminum with a thickness of $10 \mathrm{~nm}$. The sample was then observed at various magnification using SEM instrument (FEI Inspect S50, USA) with voltage was set at $20 \mathrm{kV}$ and $12 \mathrm{~mA}$ [16].

\section{Thermal analysis by DSC}

DSC was performed using Mettler Toledo. About $4 \mathrm{mg}$ of each sample was placed in crimped sample pan. The sample was heated from 30 to $300^{\circ} \mathrm{C}$ at a heating rate of $10^{\circ} \mathrm{C} /$ minutes under nitrogen purged [18].

\section{Characterization by PXRD}

PXRD (Phillips X'Pert diffractometer) analysis was performed at room temperature. Condition of measurement was set as follows: $\mathrm{Cu}$ metal target, $\mathrm{K} \alpha$ filter, voltage of $40 \mathrm{kV}$, and $40 \mathrm{~mA}$. The analysis was performed on the range of $2 \theta$ of $5-40^{\circ} \mathrm{C}$. Sample was placed on the sample holder and flatted to prevent particle orientation during preparation [16].

\section{Characterization by FTIR}

IR spectra were recorded using Jasco 4200-type A. The dried pure AS acid, physical mixture, and binary system were previously ground and mixed thoroughly with potassium bromide. The IR spectrum was obtained using IR spectrophotometer in wave length range of $400-4000 / \mathrm{cm}$ [17].

\section{RESULTS AND DISCUSSION}

The cocrystallization process of AS cocrystal was observed under polarized microscope. Polarizing light microscopy is particularly useful for studying the optical properties of crystals. When crossed polarized light (the vibration directions of the two polarizers are oriented $90^{\circ} \mathrm{C}$ from one another) passes through an anisotropic crystal, the crystal will show bright interference colors, as long as it is not in an extinction position or aligned on an optic axis [19]. As shown in Fig. 1, AS cocrystal has unique crystal habit.

The phase diagram of AS binary system consists of different molar ratio of AS acid. The result indicated that the molar ratio of 50:50\% show a decreased melting temperature of each component. Acyclovir melted at $253.53^{\circ} \mathrm{C}$ and succinic acid melted at $187.29^{\circ} \mathrm{C}$, whereas the binary system of AS melted at $176.23^{\circ} \mathrm{C}$. Decreasing of melting temperature exhibited that it formed a cocrystal as shown in Fig. 2 and Table 1.

DSC is thermal analysis method to evaluate changes in thermodynamic properties that occur when the material supplied heat energy. Changes can be observed in the process of melting, recrystallization or solid phase transformations indicated by endothermic or exothermic peaks. Fig. 3 showed new endothermic peak appears at $176.23^{\circ} \mathrm{C}\left(\Delta \mathrm{H}=1.07 \mathrm{Jg}^{-1}\right)$ for AS physical mixture; $177.45^{\circ} \mathrm{C}\left(\Delta \mathrm{H}=0.87 \mathrm{Jg}^{-1}\right)$ for AS cocrystal (ethanol) and $178.41^{\circ} \mathrm{C}\left(\Delta \mathrm{H}=0.78 \mathrm{Jg}^{-1}\right)$ for AS cocrystal (glacial acetic acid). The thermal behavior of the cocrystals was distinct with a different melting transition from that seen with either of the individual components; this suggests the formation of a new phase [11]. The changes in peak position may be attributed to change in powder geometry of samples during preparation [20].

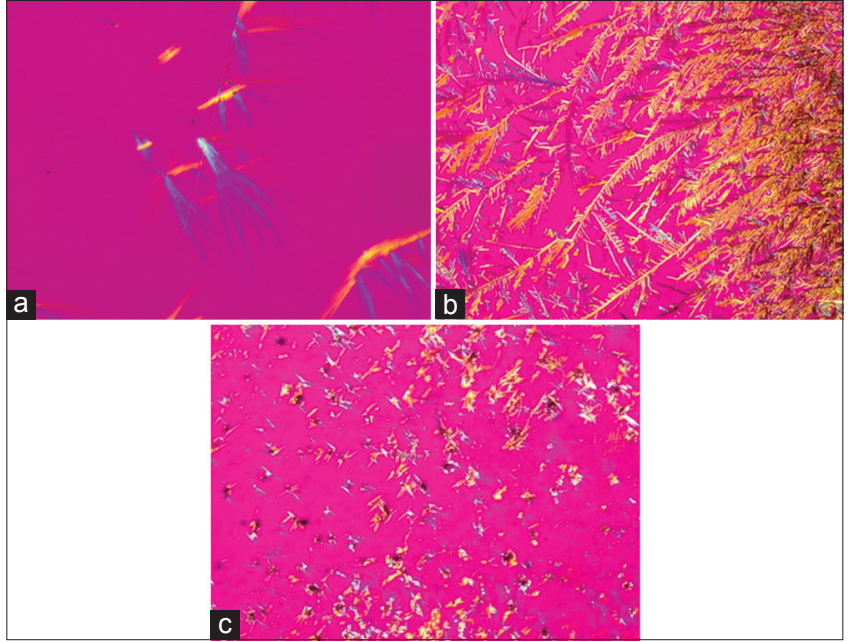

Fig. 1: Photomicroscope (a) acyclovir, (b) succinic acid (c) acyclovir-succinic cocrystal

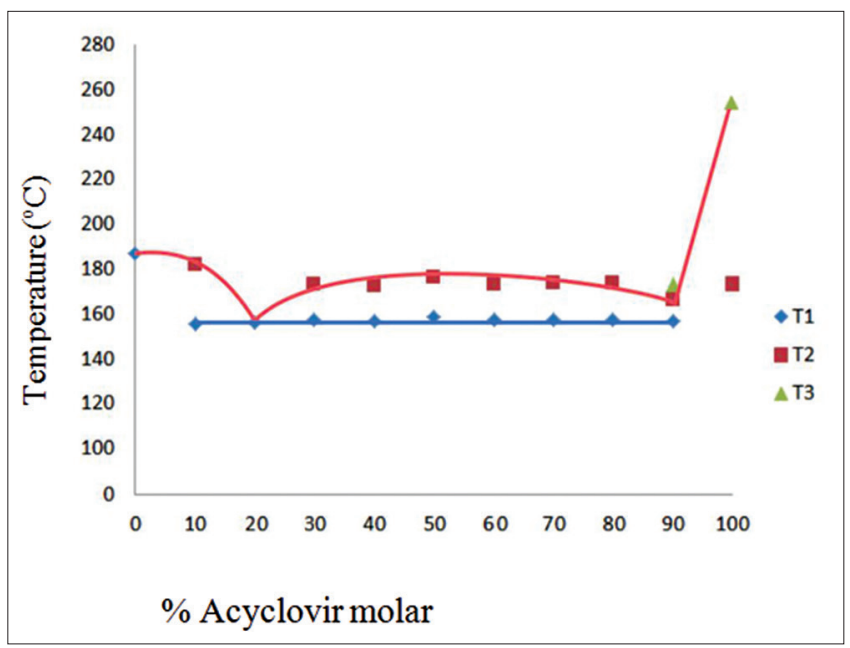

Fig. 2: Phase diagram of acyclovir-succinic binary systems with various composition

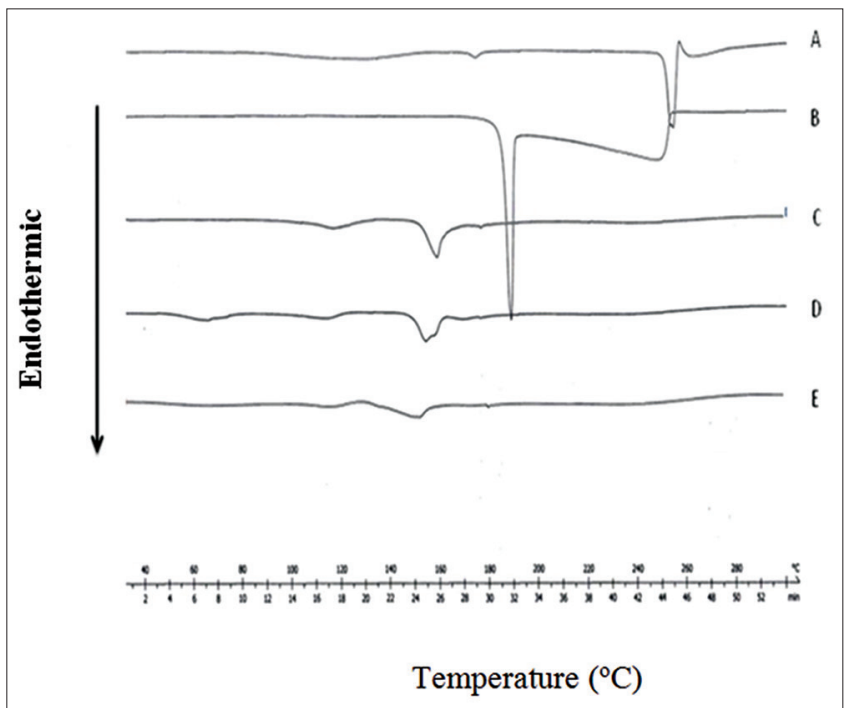

Fig. 3: Differential scanning calorimetry thermogram. (A)

Acyclovir, (B) succinic acid, (C) physical mixture acyclovirsuccinic (AS) (1:1), (D) cocrystal of AS in ethanol, (E) cocrystal of AS in glacial acetic acids. Arrow sign $(\downarrow)$ show specific diffraction peak in cocrystal of AS 
Since every compound produces its own characteristic powder pattern owing to the unique crystallography of its structure, PXRD is clearly the most powerful and fundamental tool for a specification of the polymorphic identity of an analyte [21].

Table 1: Endothermic of AS acid and binary systems of AS in various composition

\begin{tabular}{llll}
\hline \multirow{2}{*}{ Sample } & \multicolumn{3}{l}{ Endothermic peak $\left({ }^{\circ} \mathbf{C}\right)$} \\
\cline { 2 - 4 } & T1 & T2 & T3 \\
\hline Succinic acid & 187.29 & - & - \\
AS physical mixture (1:9) & 155.64 & 181.68 & - \\
AS physical mixture (2:8) & 156.08 & - & - \\
AS physical mixture (3:7) & 157.15 & 173.42 & - \\
AS physical mixture (4:6) & 156.65 & 172.27 & - \\
AS physical mixture (5:5) & 158.42 & 176.23 & - \\
AS physical mixture (6:4) & 157.45 & 172.99 & - \\
AS physical mixture (7:3) & 157.35 & 173.62 & - \\
AS physical mixture $(8: 2)$ & 157.40 & 173.75 & - \\
AS physical mixture (9:1) & 156.91 & 166.37 & 173.14 \\
Acyclovir & - & 174.01 & 253.53 \\
\hline
\end{tabular}

AS: Acyclovir-succinic

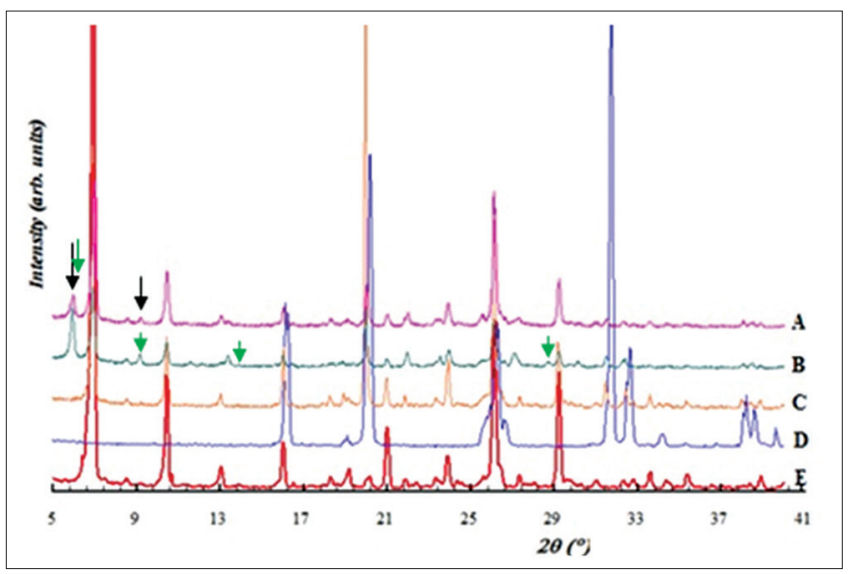

Fig. 4: Powder X-ray diffraction. (A) Cocrystal of acyclovir-succinic (AS) (acetic acid), (B) cocrystal of AS (ethanol), (C) physical mixture of AS (1:1), (D) succinic acid, (E) acyclovir
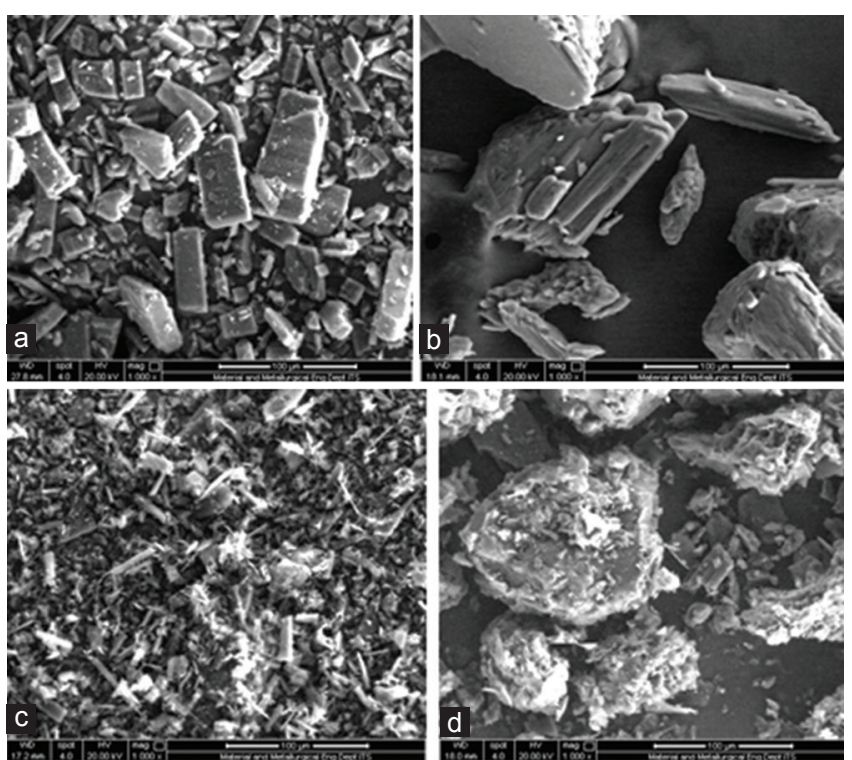

Fig. 5: Microphotographs of (a) acyclovir, (b) succinic acid, (c) acyclovir-succinic (AS) cocrystal (ethanol), (d) AS cocrystal (glacial acetic acid)
New crystalline phase is formed from the interaction between the two components will be observed clearly from the XRD. Fig. 4 showed the PXRD of AS cocrystals compared to the single component and physical mixture of both components without treatment. The PXRD pattern of AS cocrystals different from the pattern of a physical mixture of AS and pure component. The PXRD pattern of AS cocrystals showed some new interference peaks typical at $2 \theta=5.91^{\circ} ; 9.16^{\circ}$; and $13.40^{\circ}$ (ethanol) and $2 \theta=5.98^{\circ} ; 9.19^{\circ}$; and $13.43^{\circ}$ (glacial acetic acid), which were not found in the diffractogram of AS acid and their physical mixture. These unique PXRD patterns of AS cocrystals indicate the formation of new crystalline phases [14]

Fig. 5 shows the microscopic analysis with a SEM. The powder of acyclovir appears in the form of particles with irregular shape and size (Fig. 5a). Succinic acid look like rod shape (Fig. 5b). The AS cocrystal (ethanol) in Fig. 5c appears like a needle shape in which the original morphology of both components has disappeared. Fig. $5 \mathrm{~d}$ performed the AS cocrystal (glacial acetic acid) with a more homogeneous aggregate mixture of AS.

The IR spectrum of acyclovir two-thirds hydrate had two peaks in the region of $3500-3300 / \mathrm{cm}$, corresponding to $\mathrm{NH}$ and $\mathrm{OH}$, respectively, and the $1600 / \mathrm{cm}$ region was represented by a band corresponding to the amide group [22]. The spectrum of succinic acid had one peak at $3439 / \mathrm{cm}$ due to $\mathrm{O}-\mathrm{H}$, and the region of $1694 / \mathrm{cm}$ showed a band corresponding to $\mathrm{C}=\mathrm{O}$ stretch [23]. The peaks due to $\mathrm{N}-\mathrm{H}$ stretching acyclovir at $3440 \mathrm{~cm}^{-1}$ are now shifted to $3442 / \mathrm{cm}$, similar both in ethanol and glacial acetic acid. The increase in the N-H stretching frequency in the AS cocrystals implies that amine group is participating in a weak hydrogen bond. In addition, the peak due to $\mathrm{C}=0$ stretching of acyclovir at 1611,1661 , and $1694 / \mathrm{cm}$ is shifted to 1612,1664 and $1693 / \mathrm{cm}$ both in ethanol and glacial acetic acid. The peak due to $\mathrm{C}=0$ stretching of succinic acid at $1694 / \mathrm{cm}$ is now present as a triple peak at 1612,1664 , and $1693 / \mathrm{cm}$. It is probably due to the stretching of the $\mathrm{C}=0$ employed in hydrogen bonds.

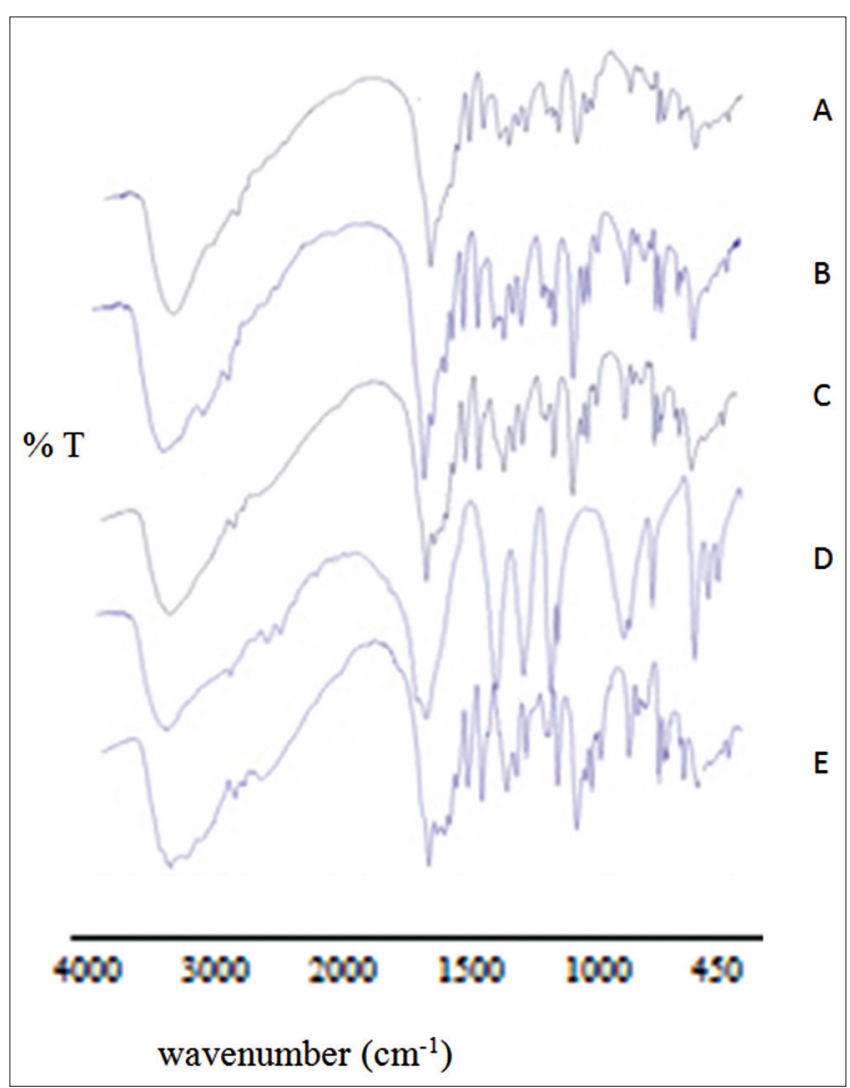

Fig. 6: Fourier transform infrared spectroscopy spectrum. (A) Acyclovir-succinic (AS) cocrystal (glacial acetic acid), (B) AS cocrystal (ethanol), (C) physical mixture of AS (1:1), (D) succinic acid, (E) acyclovir 
A bathochromic shift in the $\mathrm{C}=0$ stretching frequency in succinic acid from 1694 to $1693 / \mathrm{cm}$ both in ethanol and glacial acetic acid further explains the formation of the AS cocrystals. Subsequently, the decrease in the $\mathrm{OH}$ stretching frequency from $3439 / \mathrm{cm}$ in succinic acid to $3442 / \mathrm{cm}$ both in ethanol and glacial acetic acid in AS cocrystals suggests that the carboxyl group is participating in a weak hydrogen bond (Fig. 6).

\section{CONCLUSION}

New crystalline phase is formed from the interaction between AS acid using solvent evaporation method. It has been characterized by polarized microscope, SEM, DSC, PXRD, and FTIR.

\section{REFERENCES}

1. Jones W, Motherwell WD, Trask AV. Pharmaceutical co-crystals: An emerging approach to physical property enhancement. MRS Bull 2006;31:875-9.

2. Shultheiss N, Newman A. Pharmaceutical and their physicochemical properties. Cryst Growth Des 2009;9:2950-67.

3. Sarma B, Chen J, Hsi H, Myerson AS. Solid forms of pharmaceuticals: Polymorphs, salts and co-crystals. Korean J Chem Eng 2011;28(2):315-22.

4. Sekhon BS. Pharmaceutical co-crystals - An update. Int Bull Drug Res 2012;1(2):24-39

5. Mingyu L, Hong BC, Yao Y, Shen H, Ji G, Li G, et al. Development of a pharmaceutical co-crystal with solution crystallization technology: Preparation, characterization, and evaluation of myricetin-proline cocrystals. Eur J Pharm Biopharm 2016;107:151-9.

6. Sevukarajan M, Thanuja B, Riyaz S, Rahul N. Synthesis and characterization of a pharmaceutical co-crystal (Aceclofenac: Nicotinamide). J Pharm Sci Res 2011;3(6):1288-93.

7. Nanjwade VK, Manvi FV, Shamrez AM, Basavaraj KN, Meenaxi MM. New trends in the co-crystallization of active pharmaceutical ingredients. J Appl Pharm Sci 2011;1(8):1-5

8. Santos OM, Reis ME, Jacon JT, Lino ME, Simoes JS, Doriguetto AC. Polimorphism: An evaluation of the potential risk to the quality of drug products from the farmacia popular rede propria. Braz J Pharm Sci 2014;50(1):1-24

9. Almarsson O, Zaworotko MJ. Crystal engineering of the composition of pharmaceutical phases. Do pharmaceutical co-crystals represent a new path to improved medicines? Chem Commun 2004;35(6):1889-96.

10. Najar AA, Azim Y. Pharmaceutical co-crystals: A new paradigm of crystal engineering. J Indian Inst Sci 2014;94(1):45-67.

11. Masuda T, Yoshihashi Y, Yonemochi E, Fujii K, Uekusa H. Cocrystallization and amorphization induced by drug-excipient interaction improves the physical properties of acyclovir. Int $\mathrm{J}$ Pharm 2012;422:160-9.

12. Bruni G, Maietta M, Maggi L, Mustarelli P, Ferrara C, Berbenni V, et al. Preparation and physicochemical characterization of acyclovir co-crystals with improved dissolution properties. J Pharm Sci 2013;102(11):4079-86

13. Yan Y, Chen JM, Lu TB. Simultaneously enhancing the solubility and permeability of acyclovir by crystal engineering approach. Cryst Eng Commun 2013;15:6457-60.

14. Sarkar A, Rohani S. Co-crystal of acyclovir with promising physicochemical properties. J Pharm Sci 2015;104:98-105.

15. Munde AV, Kumar FN, Radheshyam BK. Co-crystallization: An alternative approach for solid modification. J Drug Ther 2013;3(4):166-72.

16. Partogi T, Soewandhi SN, Pamudji JS, Wikarsa S. Identification of physical interaction between anti malarial drugs combination artesunateamodiaquine hydrochloride. Int J Pharm Pharm Sci 2013;5(3):206-10.

17. Setyawan D, Sari R, Yusuf H, Primaharinastiti R. Preparation and characterization of artesunate-nicotinamide co-crystal by solvent evaporation and slurry method. Asian J Pharm Clin Res 2014;7(1):62-5.

18. Alatas F, Soewandhi SN, Sasongko L, Ismunandar, Uekusa H. Cocrystal formation between didanosine and two aromatic acids. Int $\mathrm{J}$ Pharm Pharm Sci 2013;5(3):275-80.

19. Reutzel-Edens SM. Analytical techniques and strategies for salt, cocrystal characterization. In: Wouters J, Luc Q, editors. Pharmaceutical Salts and Co-crystals. RSC Drug Discovery Series No. 16. Cambridge: Royal Society of Chemistry Publishing; 2012. p. 220.

20. Allam AN, Naggar VF, El Gamal SS. Formulation and physicochemical characterization of chitosan/acyclovir co-crystals. Pharm Dev Technol 2013;18(4):856-65.

21. Brittain HG. Polymorphism in Pharmaceutical Solids. New York: Marcel Dekker; 1999.

22. Barboza F, Vecchia DD, Tagliar MP, Silva MA, Stulzer HK. Differential scanning calorimetry as a screening technique in compatibility studies of acyclovir extended release formulations. Pharm Chem J 2009;43:363-8.

23. Ober CA, Gupta RB. Formation of itraconazole-succinic acid cocrystals by gas antisolvent cocrystallization. AAPS Pharm Sci Technol 2012;13(4):1396-405. 